\title{
Enthalpy of Formation of Phosphorus Pentachloride; Derivation of the Enthalpy of Formation of Aqueous Orthophosphoric Acid
}

\author{
R. H. Schumm, E. J. Prosen, and D. D. Wagman \\ Institute for Materials Research, National Bureau of Standards, Washington, D.C. 20234
}

(February 1, 1974)

\begin{abstract}
When chlorine (real gas, $980 \mathrm{mmHg}$ ) combines with white $(\alpha)$ phosphorus to form phosphorus pentachloride at $24.89^{\circ} \mathrm{C}, 3986.3 \pm 2.7 \mathrm{~J}$ of heat are liberated per gram of stoichiometrically equivalent $\mathrm{Mg}_{2} \mathrm{P}_{2} \mathrm{O}_{7}$. This value was determined by a dead-ended flow system in an electrically calibrated isoperibol calorimeter. Correction was made for the formation of up to one mol percent $\mathrm{PCl}_{3}$ in the products; no other impurities were found. From this value, the standard $\left(25{ }^{\circ} \mathrm{C}\right.$, ideal gas) enthalpy of formation of $\mathrm{PCl}_{5}(\mathrm{c})$ is calculated to be $-443.85 \pm 0.30 \mathrm{~kJ} / \mathrm{mol},-106.08 \pm 0.07 \mathrm{kcal} / \mathrm{mol}$. When this figure is combined with a recent determination of the enthalpy of hydrolysis of $\mathrm{PCl}_{5}(\mathrm{c})$, the standard enthalpy of formation of $\mathrm{H}_{3} \mathrm{PO}_{4}\left(\mathrm{aq}, 100 \mathrm{H}_{2} \mathrm{O}\right.$ ) is calculated to be $-1296.5 \pm 1.5 \mathrm{~kJ} / \mathrm{mol}$, in good agreement with two other values which involve the formation and hydrolysis of $\mathrm{P}_{4} \mathrm{O}_{10}$ (hex). A "best value" is suggested: $\Delta H f^{\circ}\left(\mathrm{H}_{3} \mathrm{PO}_{4}, 100 \mathrm{H}_{2} \mathrm{O}\right)=-1295.8 \pm 1.3 \mathrm{~kJ} / \mathrm{mol},-309.7 \pm 0.3 \mathrm{kcal} / \mathrm{mol}$.
\end{abstract}

Key words: Enthalpy of formation; phosphoric acid; phosphorus pentachloride.

\section{Introduction}

The direct chlorination of phosphorus, followed by dissolution in water of the resulting phosphorus pentachloride, provides a convenient thermochemical path to aqueous orthophosphoric acid. The most recent selection of the enthalpy of formation of the latter compound, given in NBS Technical Note 270-3 [1], ${ }^{1}$ is based on the bomb combustion of phosphorus followed by dissolution of phosphorus pentoxide in water [2]. Both steps of this latter path are subject to certain difficulties (see sec. 9); therefore the present work was undertaken as an independent check.

A preliminary value of the enthalpy of formation of phosphorus pentachloride based on the present work was cited in [1]. No other values in that review publication were based on $\mathrm{PCl}_{5}$. Since the completion of the present work a number of investigations related to the enthalpy of formation of aqueous orthophosphoric acid have been published; these are discussed following the description of our results. On the basis of our work and these recent investigations, we derive a value for the enthalpy of formation of aqueous orthophosphoric acid. Our laboratory work was carried out during the period May 1, 1963, through January 10, 1964.

\section{Materials}

The white $(\alpha)$ phosphorus employed in the present work was obtained by fractional sublimation, with continuous removal of impurities, at room temperature from the commercial form (yellow sticks under water) in the all-glass, greaseless apparatus shown to scale in figure 1. After the reaction ampoules (D) were flame-baked at $10^{-5} \mathrm{mmHg}^{2}$ and sealed off at $\mathrm{S}_{1}$, the rest of the apparatus was pressurized with nitrogen and opened at $\mathrm{A}$. The liquid yellow phosphorus was transferred under water against a stream of backflushing nitrogen through $S_{2}$. The apparatus was then sealed at $S_{2}$ and pumped down to $10^{-3} \mathrm{~mm} \mathrm{Hg}$ to remove the water. After the solidified phosphorus was dry and had begun to sublime over at $25^{\circ} \mathrm{C}$ (equilibrium vapor pressure $=0.04 \mathrm{mmHg}[3]$ ), an ice bath was placed around the condenser $(C)$. During the next twenty hours, while the pumping continued at $10^{-3}$ $\mathrm{mmHg}$, about ninety percent was trapped in the condenser $(\mathrm{C})$ at $0{ }^{\circ} \mathrm{C}$ (equilibrium vapor pressure $=$ $0.005 \mathrm{mmHg}$ [3]) as colorless well-formed crystals, while some phosphorus vapor with impurities was continuously carried on to the liquid-nitrogen trap (E). The pressure was then reduced to less than $10^{-5}$ 


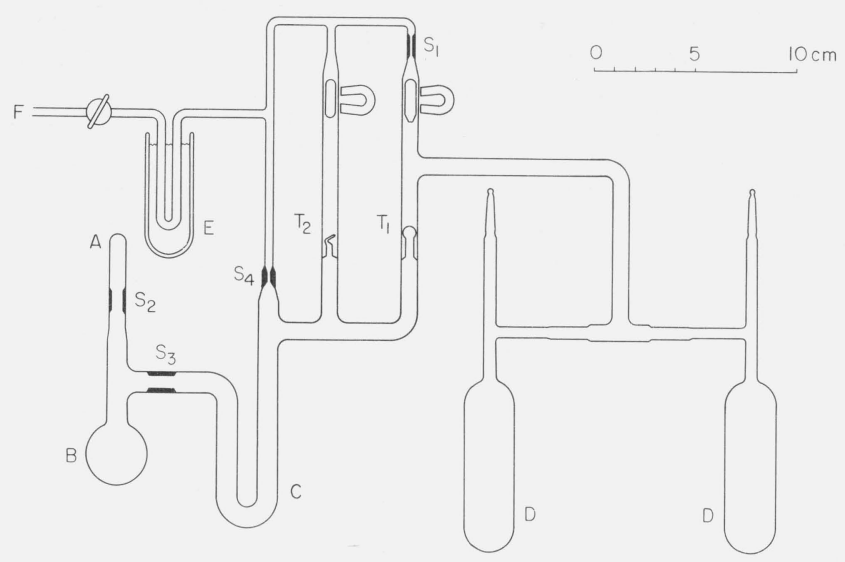

FigURE 1. The fractional sublimation line for phosphorus.

A, Loading port for yellow P; B, Yellow-P chamber; C, White-P condenser; D, Reaction ampoules; $E$, Trap cooled in liquid nitrogen; $F$, High vacuum; $S_{1}, S_{2}$, Seal-off; $S_{3}$, Seal-off, $6 \mathrm{~mm}$ i.d.; $\mathrm{S}_{4}$, Seal-off, $2 \mathrm{~mm}$ i.d.; $\mathrm{T}_{1}, \mathrm{~T}_{2}$, Internal break seals.

$\mathrm{mmHg}$ by a mercury-diffusion pump, all parts containing phosphorus were cooled by liquid nitrogen, and the yellow-phosphorus chamber (B) was sealed at $S_{3}$. The previously baked, sealed reaction ampoules were opened to the line by breaking the internal break seal $\mathrm{T}_{1}$ and then seal $\mathrm{S}_{4}$ was made. The sublimed white phosphorus, now in an evacuated isolated system, was transferred at about $25{ }^{\circ} \mathrm{C}$ to the reaction ampoules (D) at $0{ }^{\circ} \mathrm{C}$ where it appeared as large, colorless, highly refractive, well-formed crystals. The apparatus was then connected to the high vacuum through $\mathrm{T}_{2}$ and the reaction ampoules were sealed off at liquidnitrogen temperature. The amount of material in the sealed ampoules (any convenient number of which could be accommodated though only two are shown) was readily maintained within 10 percent of a nominal value by measuring the amount of yellow phosphorus placed in the apparatus, with about 10 percent allowance for loss, and by keeping the vapor paths to the reaction ampoules approximately equal. All steps were carried out with moderate precautions to exclude daylight in order to avoid the UV-catalyzed reversion to the yellow form. Incandescent illumination did not seem to catalyze this transformation.

The chlorine gas was taken from a commercial 5-lb (net) cylinder of liquid chlorine with a stated purity of 99.5 percent minimum. The chlorine was dispensed by a halogen-gas-service pressure regulator through a short drying tower of $\mathrm{Mg}\left(\mathrm{ClO}_{4}\right)_{2}$ and $\mathrm{P}_{4} \mathrm{O}_{10}$ into the chlorine delivery line. Below the regulator, the exposed parts of which were monel metal, borosilicate glass was used; some of the joints were made up with a hard laboratory wax which showed no deterioration after extensive exposure to the chlorine gas. Two needle valves made of borosilicate glass and fluorocarbon materials were also incorporated in the line.

After completion of the chlorination runs the purity of the chlorine remaining in the cylinder was determined by allowing it to react with mercury and analyzing the unreacted gas. A sample from the chlorine supply line was collected in a glass vessel provided with fluorocarbon-lubricated stopcocks. It was then connected to an all-glass line containing a reservoir of mercury which was provided with pressure and vacuum connections for regulation of the height of the mercury. Air was removed from the line by connection to a high-vacuum line, the mercury was permitted to rise to the lower cut-off stopcock of the sample vessel and the stopcock was opened. Reaction took place slowly in the absence of water vapor. Water vapor was found to accelerate the reaction, but was not used. Some seconds were required for the appearance of a tarnish on the mercury mirror, which gradually went over to a grey material. The reaction proceeded at this slow steady rate, even after the mercury had been thoroughly covered with the reaction product, and was complete in 6 to $10 \mathrm{~h}$. In order to avoid the formation of an opaque mercury mirror on the interior glass surface, the mercury in the sample vessel was not agitated. Upon standing overnight, the mercury, covered with a large amount of the grey, irregularly shaped reaction product, rose to the top of the sample vessel which terminated in a capillary (1.3 $\mathrm{mm}$ i.d.) closed by the upper stopcock which communicated through another stopcock to a small, calibrated, evacuated receiver. The narrowness of the capillary prevented the rise of the mercurychlorine reaction product so that a clean mirror-bright mercury surface appeared below the stopcock. The stopcock was opened and the unreacted gas together with clean mercury was pushed through into the calibrated receiver. The upper stopcock of the vessel was then closed, leaving some mercury in the receiver, and the mercury was brought back to the bottom of the sample vessel, thus permitting the release of unreacted gases trapped in the solid reaction product. The mercury was again permitted to rise, pushing additional gas above a mirror-clean mercury surface into the capillary. The upper stopcock of the vessel was opened, and the additional gas was added to the receiver. After a dozen passes of this kind, additional gas appearing in the capillary portion amounted to about $1 \mathrm{ppm}$ of the original sample. The mercury was then raised for the final time into the calibrated portion of the receiver and the pressure and volume of the total gaseous nonreacting impurity were read.

The original $\mathrm{Cl}_{2}$ sample $\left(325 \mathrm{~cm}^{3}\right.$ at $1060 \mathrm{mmHg}$, $\left.26^{\circ} \mathrm{C}\right)$ contained $0.05 \mathrm{~mol}$ percent $\left(4.5 \mathrm{~cm}^{3}\right.$ at $42 \mathrm{~mm} \mathrm{Hg}$, $25^{\circ} \mathrm{C}$ ) of gases which would not react with dry mercury. The unreacted gases were analyzed mass spectrometrically by the Analytical Chemistry Division and found to consist of, as ppm of the total sample: air, 20; $\mathrm{CO}_{2}, 274 ; \mathrm{CCl}_{4}, 80 ; \mathrm{CH}_{3} \mathrm{CHCl}_{2}, 5 ; \mathrm{HCl}, 55$; and $\mathrm{H}_{2} \mathrm{O}$, 65.

\section{Apparatus}

The calorimeter that was used in the measurements is shown to scale in figure 2. It was designed to permit calorimetric hydrolysis of the reaction products but this step was not used in the present work.

All screw-threaded parts were constructed of brass except for the polymethylmethacrylate plug (L) and 


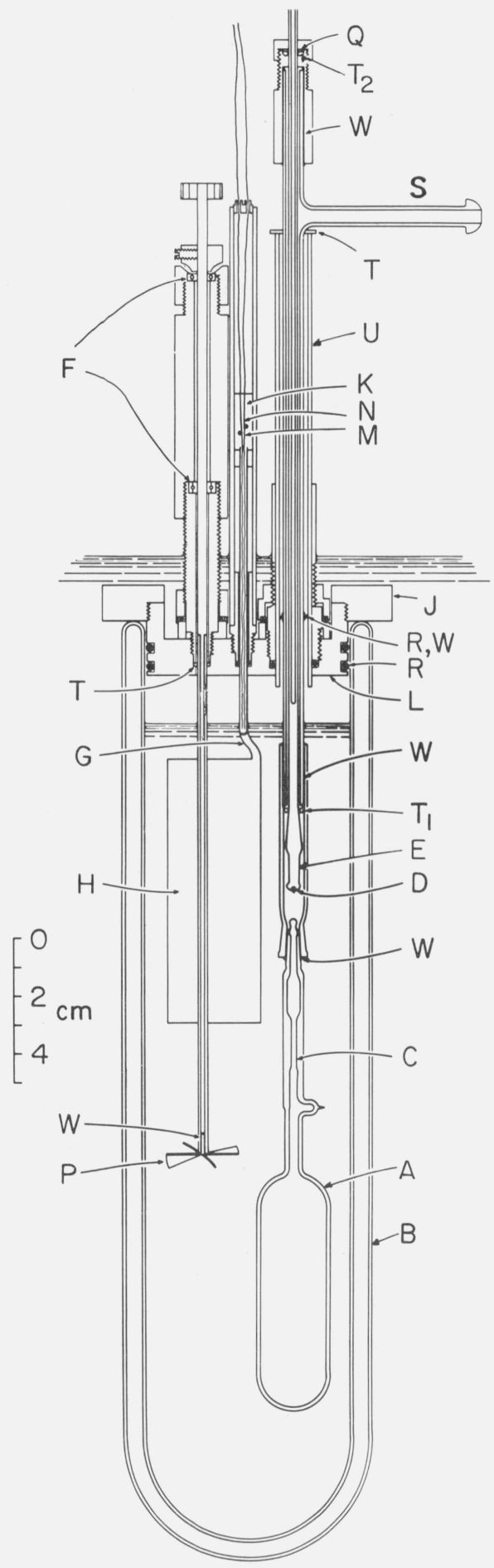

FigURE 2. The submarine isoperibol calorimeter.

A, Reaction ampoule; B, Dewar vessel; C, 0.042-Inch i.d. glass tubing; D, Diamond mounted in wax; E. Bubble breaker; F. 1/8-Inch ball bearings; G. 0.10-Inch o.d. $\times 0.01$ inch-wall platinum tubing; H, Heater encased in platinum; J, Aluminum flange; K, Bees wax; L. Machined polymethylmethacrylate plug; M, 30-Gage copper wire; N. 18-Gage copper wire; P, Platinum stirrer; Q, Brass washer; R, Rubber O-ring; S, Chlorine-inlet tube with spherical glass joint; T, Polytetrafluoroethylene washer; $\mathrm{T}_{1}, \mathrm{~T}_{2}$, Polytetrafluoroethylene O-rings; U, Glass chimney; W, Hard laboratory wax.

the aluminum flange $(J)$. The parts which pass through the plug $(\mathrm{L})$ were made of borosilicate glass except for the platinum tubing $(\mathrm{G})$. The glass chimney (U) was originally part of a device against which the reaction ampoule (A) was to be broken for the hydrolysis reaction.

The diamond-tipped ampoule opener (E) was manipulated from the top of the chlorine-inlet tube (S) through the brass stuffing box which contained a fluorocarbon O-ring $\left(\mathrm{T}_{2}\right)$ lubricated with fluorocarbon grease. A small area of the brass (Q) in the stuffing box, which was exposed to chlorine, suffered a discoloration during preliminary experiments but no further change occured on subsequent exposure to chlorine.

The fluorocarbon O-ring $\left(\mathrm{T}_{1}\right)$ fitted loosely at the upper portion of the flared bottom of the ampoule opener $(\mathbf{E})$ and permitted communication to the top of the reaction ampoule $(\mathrm{A})$ until the breaker $(\mathrm{E})$ was raised at the end of the reaction period.

There was no exit from the reaction ampoule.

The Dewar vessel (B) was a standard l-quart flask.

The calorimetric heater $(\mathrm{H})$ was shaped as a flat blade, about $1.5 \mathrm{~mm}$ thick. It was made of 160 turns (noninductive) of No. 36 AWG enameled manganin wire, wrapped over a thin sheet of mica $82 \mathrm{~mm}$ long and $28 \mathrm{~mm}$ wide, and fixed with coil dope. Leads of No. 30 AWG copper wire (M) (enameled and silkwound) were hard-soldered to ends of the heater winding which was then placed in the platinum sheath; the two No. 30 AWG copper leads protruded about $7 \mathrm{~mm}$ above the tube $(\mathrm{G})$ that extended out from the top of the heater blade (that is, $93 \mathrm{~mm}$ above the estimated calorimetric boundary). The seams of the platinum sheath were soldered with gold. The No. 30 AWG copper leads $(0.00339 \Omega / \mathrm{cm}$, measured) were soft-soldered, each, to $537 \mathrm{~mm}$ of No. $18 \mathrm{AWG}$ copper (N) $(0.000222 \Omega / \mathrm{cm}$, measured) which made demountable contacts through $\mathrm{Hg}$ amalgam to copper busbars ( $0.001 \Omega$ for the sum of the resistances of the bars) which were connected to the current-carrying leads and the potential-measuring leads of the electrical measuring circuit. In order to determine the actual temperature of the heating coil during calibration runs, its resistance, with leads, was measured potentiometrically between 0 and $50{ }^{\circ} \mathrm{C}$ in series with a $1000-\Omega$ standard resistor at a measuring current of $0.1 \mathrm{~mA}$. Its resistance was found to be

$$
\begin{aligned}
R_{t}=1068.167\left[1+5.69 \times 10^{-6}(t-25)\right. & \\
& \left.-6.38 \times 10^{-7}(t-25)^{2}\right] \Omega,
\end{aligned}
$$

and

$$
R_{\max }=1068.180 \Omega \text { at } 29.5{ }^{\circ} \mathrm{C},
$$

where $t$ is the temperature in ${ }^{\circ} \mathrm{C}$ of the stirred water bath in which the heater was immersed. The average resistance of the heater which carried $112 \mathrm{~mA}$ during heating periods of the calibration runs ranged between 1067.995 and $1067.945 \Omega$ (with leads) corresponding to temperatures between 46 and $48{ }^{\circ} \mathrm{C}$. The resistance of the leads between the estimated calorimetric boundary $( \pm 5 \mathrm{~mm})$ and the potential taps on the busbars was calculated from the above figures to be 
$0.088 \pm 0.004 \Omega$. The energy dissipated in the extracalorimetric leads, about 0.008 percent of that measured, was subtracted from the total to obtain the amount added to the calorimetric system.

The stirrer $(\mathrm{P})$ was turned at a rate of about $950 \mathrm{rpm}$ by a belt drive from a synchronous motor.

The platinum-resistance thermometer (not shown; behind the plane of fig. 2), Cyril H. Meyers No. 274, was a single-helix coil of platinum, ${ }^{3}$ about 4 -cm long in a thin-wall 9-mm o.d. glass tube. The top of the Pt coil (i.e., the junctions of the gold leads) was $97 \mathrm{~mm}$ below the surface of the calorimetric liquid. At $24{ }^{\circ} \mathrm{C}$, the thermometer had a resistance of $29.8966 \Omega$, and a temperature coefficient of $0.100767 \Omega /{ }^{\circ} \mathrm{C}$.

The electrical energy was measured by a circuit basically the same as that described in [4, 5, and 6]. Steady current from a bank of large storage batteries was switched by a solenoid, as required, between the calorimeter heater and a dummy coil of similar resistance. A steady EMF of $120 \mathrm{~V}$ dc was applied to the busbars in all calibration experiments. A $0.1-\Omega$ standard resistor (potential drop, $12 \mathrm{mV}$ ) was used for the current measurement; the voltage applied at the busbars was measured in a parallel-connected voltage divider consisting of a $10-\Omega$ standard resistor (potential drop, $60 \mathrm{mV}$ ) in series with two $10,000-\Omega$ standard resistors. Potential drops across the resistors were measured using a White double potentiometer [4] (range 0 to $100 \mathrm{mV}$ ), which, at the conclusion of the series of runs, was calibrated for internal consistency of steps on the two largest decades. The dial corrections (max: $1.3 \mu \mathrm{V}$ ) agreed well with an absolute calibration made in 1943 by the Resistance Section, NBS. An auxiliary circuit consisting of a $100-\Omega$ and a $1,000-\Omega$ standard resistor was used to establish a $100 / 1100$ fraction of standard cell voltage for determination of potentiometer ratio [5] at the conclusion of each run. Interpolations of the last-dial readings to zero galvanometer deflection, correction for external parasitic emf (usually zero, sometimes barely detectable), dial corrections (from the present calibration), and potentiometer ratio $(0.9998958$ to 0.9999586$)$ were applied. The solenoid switch, a common de relay, was manually armed prior to a selected second, triggered by a second relay activated by an amplified pulse of the NBS time signal, and then promptly bypassed and rearmed for the reverse switching operation. (The arming process resets the electrical circuits so that in each relay the movement of the armature is the same in the forward and reverse switching operations.) The electrical elements used in the calibration had recently been certified by the Electricity Division, NBS: the saturated cadmium standard (i.e., Weston normal) cell, thermostated at $30.2{ }^{\circ} \mathrm{C}$, had a voltage of $1.018091 \mathrm{~V} \pm 3 \mu \mathrm{V}$ and the standard resistors were certified to $\pm 7 \mathrm{ppm}$. Additional small circuit resistances in connecting wires, where applicable, were measured

\footnotetext{
${ }^{3}$ Certain commercial materials and equipment are identified in this paper in order adequately to specify the experimental procedure. In no case does such identification imply the recommendation or endorsement of the National Bureau of Standards, nor does it imply that the material or equipment is best for the purpose.
}

to within $2 \mathrm{ppm}$ of the total circuit resistance involved.

The masses of the $\mathrm{Mg}_{2} \mathrm{P}_{2} \mathrm{O}_{7}$ (see sec. 5 ) in the crucibles (about $20 \mathrm{~g}$ with crucible) were obtained by the substitution mode of weighing on a balance of sensitivity of $5 \mathrm{div} / \mathrm{mg}$ (20-g load) and standard deviation of $\pm 0.1 \mathrm{div}(0.020 \mathrm{mg})$. The weighings of a crucible with and without $\mathrm{Mg}_{2} \mathrm{P}_{2} \mathrm{O}_{7}$ always involved the same integral-gram pieces of the weight set, the difference being accounted for by the fractional-gram pieces only. The net change in the number of weights used never amounted to more than seven pieces. The fractionalgram pieces were intercompared in an internal calibration using the reversal mode of weighing. These weighing observations were found to agree within $0.020 \mathrm{mg}$ of the differences given by an official Class-S calibration by the NBS Mass Section in 1961, which was used for corrections to the nominal values of the weights in calculating the masses of the $\mathrm{Mg}_{2} \mathrm{P}_{2} \mathrm{O}_{7}$. Buoyancy corrections were made on all weighings of $\mathrm{Mg}_{2} \mathrm{P}_{2} \mathrm{O}_{7}$ (sec. 7).

\section{Experimental Procedure}

The chlorination runs were carried out with about $0.6 \mathrm{~g}$ of white phosphorus, except in the case of Run No. $2(0.97 \mathrm{~g})$. A sealed reaction ampoule was first attached to the bottom of the chlorine inlet tube with a fresh portion of wax and the bottom of the ampoule was cooled to remove any phosphorus from the upper tubular portions by vaporization.

The amount of water used in the calorimeter was adjusted for each run, based on the measured external volume of the reaction ampoule, to maintain the same level in the Dewar flask throughout the series of runs and calibrations.

After assembly, the calorimeter was placed in the water bath and the spherical-joint connection to the chlorine supply line was made up with wax. The lines were then alternately evacuated to the break-bubble on the reaction ampoule and pressurized with chlorine a few times, after which the line was maintained at about $200 \mathrm{mmHg}$ above atmospheric pressure with all supply valves fully open while spilling out a few $\mathrm{cm}^{3} / \mathrm{min}$ to waste. After an initial warm-up to a temperature conveniently below the starting temperature, the calorimetric system was allowed to coast until the temperature rise assumed a steady foreperiod rate. At the end of the 20-minute foreperiod, during which time the temperature was read every two minutes on the platinum resistance thermometer, the chlorinespill valve was closed and the bubble inlet on the ampoule was broken by depressing the breaker (E).

Reaction began spontaneously, proceeded at a steady rate as shown by the temperature rise $(0.6$ to $1.1^{\circ} \mathrm{C} / \mathrm{min}$, depending on the individual run) with a bright yellow-green flame of somewhat fluctuating intensity, and terminated abruptly. Reactions in preliminary experiments, conducted with well-evacuated thin wall ampoules, proceeded with a fluctuating slower rate, terminated with a gradually decreasing rate, and resulted in unreacted phosphorus in the products. 
Thick-wall ampoules (about $1.2 \mathrm{~mm}$ thick) were found to be essential for a good reaction. A separate study of the air-conductance of the line indicated that, at the rates of flow of chlorine gas during the reaction periods, all parts of the line remained at atmospheric pressure or greater. Temperature readings were taken every $0.2{ }^{\circ} \mathrm{C}$ during the fast part of the temperature rise, which amounted to about $2.5^{\circ} \mathrm{C}$. Reaction stopped abruptly after $4 \mathrm{~min}$, whereupon the chlorine pressure was reduced to atmospheric and the chlorine inlet to the ampoule was closed by drawing up the breaker $(\mathrm{E})$ so that the wide part of the glass sealed the chlorine inlet at the fluorocarbon O-ring $\left(\mathrm{T}_{1}\right)$. After the fast temperature rise, about $15 \mathrm{~min}$ were required for "equilibration." During this time the temperature was read every minute. After a total reaction period of $22 \mathrm{~min}$, readings were taken every $2 \mathrm{~min}$ during a 20 min after-period.

The calorimeter was disassembled and the reaction ampoule was removed by warming the wax. The reaction ampoule was then broken open at the neck and the contents were immediately analyzed as described in section 5 .

Electrical calibrations were carried out with an empty reaction ampoule. The chlorine inlet tube $(\mathbf{S})$ was not connected to the chlorine-supply line. Heating times of $12 \mathrm{~min}$ and total reaction periods of $22 \mathrm{~min}$ were used.

\section{Chemical Analysis of Products}

The contents of the reaction ampoule, consisting of $\mathrm{PCl}_{5}, \mathrm{PCl}_{3}$, and unreacted chlorine gas, were hydrolyzed by aqueous hydrazine hydrochloride. This reduced the free chlorine to chloride ion and converted the $\mathrm{PCl}_{5}$ and $\mathrm{PCl}_{3}$ to phosphoric and phosphorous acids. Phosphorous acid was determined iodimetrically in one aliquot following a selective oxidation of the excess hydrazine by iodine. Total phosphorous was determined gravimetrically as orthophosphate in separate duplicate aliquots after the lower valence forms of phosphorus had been oxidized by bromine. The details of these procedures and examination of the reaction products for other phosphorus compounds are described in the remainder of this section.

The disengaged ampoule containing the reaction products was broken open at the neck, just above the reaction chamber, and the small amount of $\mathrm{PCl}_{5}$ in the tubular portion was washed with water into approximately $200 \mathrm{~cm}^{3}$ of water containing $100 \mathrm{mg}$ of hydrazine dihydrochloride in a $500-\mathrm{cm}^{3}$ Erlenmeyer flask with fluorocarbon-gasketed glass-stoppered closure. The reaction chamber, containing nearly all the products of reaction, was then placed in the Erlenmeyer flask which was tightly closed and shaken. The first portion of water to enter the chamber caused a rapid evolution of $\mathrm{HCl}$ gas which violently expelled the unreacted chlorine and resulted in a momentary pressure rise in the Erlenmeyer flask. The chamber then immediately filled with the aqueous solution and the remaining $\mathrm{PCl}_{5}$ was converted to liquid $\mathrm{POCl}_{3}$ which, in a few minutes, was hydrolyzed to $\mathrm{H}_{3} \mathrm{PO}_{4}$ and more $\mathrm{HCl}$. The contents of the Erlenmeyer were then washed through a No. 40 (Whatman) paper into a l-litre volumetric flask. The total amount of phosphorus was determined in duplicate volumetric 200/1000 aliquots. Duplicate $50 / 1000$ aliquots were also taken, diluted to approximately $200 \mathrm{~cm}^{3}$, and treated in the same manner as the larger aliquots as a check of completeness of analytical recovery. The temperatures of the volumetric glassware were noted, where applicable, and corrections were made on the basis of recent calibrations. The aliquots, about $0.1 \mathrm{~N}$ in $\mathrm{HCl}$, were exposed overnight to bromine [7] vapors in a closed space, acquiring a deep bromine color, and were then heated for a few hours to about $80^{\circ} \mathrm{C}$ to drive off the excess bromine. The phosphorus was precipitated, dissolved, and reprecipitated as $\mathrm{MgNH}_{4} \mathrm{PO}_{4}$ [8], filtered on a crucible of Selas sintered procelain of porosity 10 and ignited to constant weight on the Selas crucible at $900^{\circ} \mathrm{C}$.

Analysis of the products of the preliminary experiments, in which the reprecipitated $\mathrm{MgNH}_{4} \mathrm{PO}_{4}$ on ashless filter paper in ordinary porcelain crucibles was ignited at $1050-1100^{\circ} \mathrm{C}$, was hindered by difficulty in obtaining constant weight. The ignited $\mathrm{Mg}_{2} \mathrm{P}_{2} \mathrm{O}_{7}$ usually showed a persistent gray to black discoloration despite efforts to burn the paper off at a temperature below $900{ }^{\circ} \mathrm{C}$ before completing the ignition. The conversion to $\mathrm{Mg}_{2} \mathrm{P}_{2} \mathrm{O}_{7}$ actually takes place at a relatively low temperature, at $250^{\circ} \mathrm{C}$ [9] or at $477^{\circ} \mathrm{C}$ [10], and filter paper, alone, can be ignited to a colorless ash at $675^{\circ} \mathrm{C}[10]$. Treatment of the precipitate with aqueous ammonium nitrate before and after ignition $[11,12]$ was ineffective in removing the discoloration. ${ }^{4}$ Ignitions on Selas crucibles without paper yielded constant weight after $\mathrm{l} \mathrm{h}$ at approximately $900{ }^{\circ} \mathrm{C}$; prolonging the ignition overnight at this temperature did not result in further weight loss.

The unreacted hydrazine dihydrochloride and the trivalent phosphorus were determined iodimetrically according to the reactions:

$$
\mathrm{N}_{2} \mathrm{H}_{4}+2 \mathrm{I}_{2}+4 \mathrm{HCO}_{3}^{-} \rightarrow \mathrm{N}_{2}+4 \mathrm{I}^{-}+4 \mathrm{H}_{2} \mathrm{O}+4 \mathrm{CO}_{2}
$$

and

$$
\mathrm{HPO}_{3}^{\overline{=}}+\mathrm{I}_{2}+2 \mathrm{HCO}_{3}^{-} \rightarrow \mathrm{HPO}_{4}^{\overline{-}}+2 \mathrm{I}^{-}+\mathrm{H}_{2} \mathrm{O}+2 \mathrm{CO}_{2} .
$$

Reaction (1) proceeds rapidly and quantitatively if the $\mathrm{pH}$ of the solution is between 7.0 and 7.4 [13]. Such solutions, however, are easily oxidized by air. Reaction (2) proceeds slowly but quantitatively [14] in sodium bicarbonate solution and is carried out with an excess of $I_{2}$ which is subsequently back titrated. A 200-ml aliquot was added to an iodine flask containing $5 \mathrm{~g}$ of $\mathrm{KI}$ and $12 \mathrm{~g}$ of $\mathrm{NaHCO}_{3}$ while flushing with $\mathrm{CO}_{2}$ (from "dry ice"). The solution, while being

\footnotetext{
${ }^{4}$ Treadwell and Hall [11] state that the precipitate can be whitened by moistening with strong acid and carefully reheating. $\mathrm{McNabb}[12]$ says that the unignited or ignited precipitate can be dissolved in $\mathrm{HNO}_{3}$, but the acid solution must be neutralized with ammonia before heating, to yield white $\mathrm{Mg}_{2} \mathrm{P}_{2} \mathrm{O}_{7}$ of correct weight.
} 
vigorously agitated and flushed with $\mathrm{CO}_{2}$, was titrated with $0.1 \mathrm{~N} \mathrm{I}_{2}$ in $0.25 \mathrm{~N} \mathrm{KI}$ to the first permanent perceptible yellow of free iodine. Then $5 \mathrm{ml}$ excess of the $0.1 \mathrm{~N}$ iodine solution was added by means of a pipette and the flask was capped, sealed with aqueous $\mathrm{KI}$, and set aside to allow reaction (2) to occur. A blank, containing similar amounts of $\mathrm{H}_{3} \mathrm{PO}_{4}, \mathrm{HCl}$ and $\mathrm{NH}_{2} \mathrm{NH}_{2} \cdot 2 \mathrm{HCl}$, was treated in a similar manner using the same volume of iodine solution. About 1 to $2 \mathrm{~h}$ later the excess iodine was back titrated with $0.0400 N$ sodium arsenite (NBS Standard Sample 83a). The difference in the back-titers was calculated as phosphite, according to eq (2).

While performing the direct iodine titration of hydrazine in the $\mathrm{CO}_{2}$-blanketed neutral solutions containing phosphite ion, vigorous agitation was maintained, by magnetic stirrer, to prevent oxidation of phosphite ion by local concentrations of $I_{2}$. The method was tested on various mixtures containing known amounts of hydrazine and phosphorous acid. It gave values for both constituents which were estimated to be accurate to \pm 0.004 milliequivalents in the aliquot.

The hydrolyzed products of the preliminary experiments, many of which contained unreacted phosphorus, were examined for various inorganic compounds of phosphorus. In one procedure, the orthophosphate in a $300 / 1000$ aliquot was separated, before bromine treatment, from the other compounds of phosphorus by precipitation and reprecipitation under $\mathrm{CO}_{2}$ as $\mathrm{MgNH}_{4} \mathrm{PO}_{4}$. The combined filtrates were then treated with bromine vapors and the converted forms of phosphorus were precipitated and reprecipitated as $\mathrm{MgNH}_{4} \mathrm{PO}_{4}$. The weight of the second precipitate from samples containing up to 7 percent phosphorous acid (based on total phosphorus) was in good agreement with the iodimetrically determined phosphite. The estimated uncertainty of the comparison, obtained from the combined uncertainties of the two methods, was $\pm 0.023 \mathrm{mmol}$ phosphorus for the whole sample. The methods agreed within this range. Becker and Johnson [15] found that a double precipitation of $\mathrm{MgNH}_{4} \mathrm{PO}_{4}$ effects a complete separation of phosphite from orthophosphate.

The amount of hypophosphite in the hydrolyzed reaction products of the preliminary runs was found by another method to be negligible. In this procedure, the sum of hypophosphite plus phosphite was determined by iodimetric oxidation in acid solution to $\mathrm{H}_{3} \mathrm{PO}_{3}$, and then, in neutral solution, to $\mathrm{H}_{3} \mathrm{PO}_{4}$ [14]. When subtracting the values obtained for phosphite in separate iodimetric phosphite determinations (by the methods described above), small negative and positive values were obtained for the amount of hypophosphite present. These values were all within the limit of error of $\pm 0.033 \mathrm{mmol} / \mathrm{run}$.

Three of the preliminary runs were examined for various phosphorus compounds by one-dimensional chromatography on Schleicher and Schuell Paper No. 589 GR. The hydrolyzed reaction products of these runs were diluted to 1 litre. Aliquots $\left(10 \mathrm{~cm}^{3}\right)$ were neutralized with ammonia, evaporated at room temper- ature to $1 \mathrm{~cm}^{3}$, and applied as single and triple spots. Some were irrigated by Ebel's basic solvent $1^{\circ}[16]$ and others by Ebel's acid solvent $1^{\circ}$. The irrigated papers were first exposed to bromine vapor to convert the nonorthophosphate areas to orthophosphate, and then were sprayed with molybdic acid, heated, and sprayed with stannous chloride to develop the molybdenum blue color. Tests of the procedure with known mixtures of orthophosphate, phosphite, hypophosphite, pyrophosphate, triphosphate, trimetaphosphate, and tetrametaphosphate showed that these compounds migrated under both acid and alkaline conditions as described by Ebel, and that the lower limit of identification of each compound was about $100 \mathrm{ppm}$ phosphorus in the solution applied to the paper. The applied spots of hydrolyzed products contained up to $15,000 \mathrm{ppm} \mathrm{P}$ (1.5 percent) as orthophosphate and $1100 \mathrm{ppm} \mathrm{P}$ as phosphite. At no time was overloading of the paper apparent. No phosphorus compounds other than orthosphosphate and phosphite were observed on the test papers irrigated by basic solution. Thus, since the lower limit of identification of any single species is $100 \mathrm{ppm}$, we may estimate, on the basis of results of the test with the product solution containing $1100 \mathrm{ppm}$ of phosphite, that the concentration of any other form of phosphorus compound is less than 10 percent of the concentration of the phosphite. Acid irrigation of papers spotted similarly showed only one spot, that of the orthophosphate and phosphite (unseparated).

Two-dimensional chromatography of a synthetic mixture first with the alkaline and then with the acid solution, resulted in the expected array of individual compounds but with reduced sensitivity, the lower limit of detection being $300 \mathrm{ppm} \mathrm{P}$ in any compound. Two-dimensional chromatograms were not made of the test solutions.

One-dimensional chromatograms were made of one sample applied as stripes in two concentrations $(3200$ and $200 \mathrm{ppm} \mathrm{P}$ as phosphate and phosphite; 9500 and $600 \mathrm{ppm} \mathrm{P}$ as phosphate and phosphite). Here the sensitivity was increased (probably because of the cancellation of the effect of lateral diffusion of the phosphorus compounds during irrigation) to an estimated $50 \mathrm{ppm}$. No species other than phosphate and orthophosphate were evident. An acid irrigation of a similarly striped paper showed only the phosphate stripe (with phosphite not separated from the phosphate).

A review of the literature indicates that there is no reason to expect the formation of species other than $\mathrm{PCl}_{5}$ and $\mathrm{PCl}_{3}$ in the products of the chlorination reaction. $\mathrm{P}_{2} \mathrm{Cl}_{4}$ has been prepared only by electrical discharge $[17,18]$; also it decomposes below $25{ }^{\circ} \mathrm{C}$. No other chlorides of phosphorus have been described as existing under normal conditions.

\section{Units and Physical Constants}

The calorie (cal) used is the thermochemical calorie which is $4.184 \mathrm{~J}$. The molecular weight of $\mathrm{Mg}_{2} \mathrm{P}_{2} \mathrm{O}_{7}$ 
is $222.5534 \pm 0.0014$, from the 1969 Table of Atomic Weigh is [19].

\section{Experimental Results}

The results of the electrical calibrations are given in table $1 . \Delta R_{c}$ corresponds to the corrected temperature rise [20] measured on the platinum resistance

TABLE 1. Results of the electrical calibrations

\begin{tabular}{c|c|c|c|c|c}
\hline \hline $\begin{array}{c}\text { Run } \\
\text { No. }\end{array}$ & $\begin{array}{c}\Delta R_{c} \\
\Omega\end{array}$ & $\begin{array}{c}\text { Mid } \\
\text { temp. } \\
{ }^{\circ} \mathrm{C}\end{array}$ & $\begin{array}{c}E_{e} \\
\mathrm{~J}\end{array}$ & $\begin{array}{c}\Delta E_{s} \\
\mathrm{~J} / \Omega\end{array}$ & $\begin{array}{c}E_{s} \\
\mathrm{~J} / \Omega\end{array}$ \\
\hline 1 & 0.240627 & 23.68 & $9,272.69$ & 592.61 & $37,942.92$ \\
2 & .251235 & 23.71 & $9,680.98$ & 589.49 & $37,944.07$ \\
3 & .251522 & 23.68 & $9,692.94$ & 593.68 & $37,943.47$ \\
4 & .246657 & 23.66 & $9,514.80$ & 578.05 & $37,996.98$ \\
5 & .245257 & 23.68 & $9,448.30$ & 579.92 & $37,944.16$ \\
6 & .258372 & 23.71 & $9,953.36$ & 580.54 & $37,942.83$ \\
7 & .246515 & 23.62 & $9,495.99$ & 579.72 & $37,941.22$ \\
\hline
\end{tabular}

Mean of Runs 1-3,

$5-7 \ldots \ldots \ldots \ldots \ldots . .23 .68$

$37,943.11$

Estimated standard deviation of the mean............ $\quad \pm 0.44$

thermometer. $E_{e}$ is the quantity of electrical energy introduced into the system. $E_{s}$ is the energy equivalent of the standard calorimetric system defined as the solid parts of the calorimeter (always wetted to the same height), $857.50 \mathrm{~g}$ water and $17.00 \mathrm{~g}$ glass reaction ampoule. $\Delta E_{s}$ is the increase in energy equivalent of the real system calculated from the specific heats of additional water used $(4.1802 \mathrm{~J} / \mathrm{g})$, the additional glass of the reaction ampoule $(0.20 \mathrm{cal} / \mathrm{g})$, the wax to attach it $(0.69 \mathrm{cal} / \mathrm{g})$ and the amount of phosphorus used (none in the calibration runs; $0.19 \mathrm{cal} / \mathrm{g}$ ). The large deviation in $E_{s}$ for run 4 is attributed to a $1 \mathrm{~s}$ error in arming the switching circuit at the end of the heating period. The water used in the calorimeter accounts for 94.4 percent of the energy equivalent.

The results of the chlorination runs, all of which proceeded rapidly and terminated abruptly, are given in table 2 . The heat produced by chlorination of the white phosphorus is expressed as joules per gram mass of $\mathrm{Mg}_{2} \mathrm{P}_{2} \mathrm{O}_{7}$ precipitated from the bromine-treated products. This quantity, denoted $h$, is calculated by the formula:
$h=f\left[\left(37,943.11+\Delta E_{s}\right) \Delta R_{c}+12.38 v\right.$

$$
-0.479(1.594 w / f+0.100) \Delta t]
$$

\section{$1.00032 w$}

$f=$ the aliquot fraction of the total of the hydrolyzed products in which, after bromine treatment, the total phosphorus was determined as $\mathrm{Mg}_{2} \mathrm{P}_{2} \mathrm{O}_{7}$.

$E_{\mathrm{S}}$ is $37,943.11 \mathrm{~J} / \Omega$ (see table 1 ).

$v=$ the difference in back-titer, $\mathrm{ml}$ of $0.0400 \mathrm{~N}$ $\mathrm{As}^{3+}$, between the blank and a $200-\mathrm{ml}$ aliquot; the quantity $12.38 v$ is the heat which would have been liberated by chlorination of the $\mathrm{PCl}_{3}$ in the products, obtained as ${ }^{5}$

$$
\frac{v(\mathrm{ml}) \times 0.0400 \mathrm{~N}}{2 \mathrm{meq} / \mathrm{mmol}} \times 5 \times 29.6 \frac{\mathrm{cal}}{\mathrm{mmol}} \times 4.184 \frac{\mathrm{J}}{\mathrm{cal}}
$$

$w=$ the weight of $\mathrm{Mg}_{2} \mathrm{P}_{2} \mathrm{O}_{7}$ in air

$\Delta t=$ the amount by which the calorimeter temperature at the end of the reaction period (the reaction temperature) is exceeded by the average room temperature.

1.594 $w / f+0.100=$ the calculated mass of chlorine consumed by the reaction, plus that required to fill, in the average case, the internal volume of the ampoule less the volume of the $\mathrm{PCl}_{5}$.

$0.479 \mathrm{~J} /{ }^{\circ} \mathrm{C} \cdot \mathrm{g}$ is the specific heat of chlorine gas [1].

$1.00032 \pm 0.00001$ is the buoyancy factor for $\mathrm{Mg}_{2} \mathrm{P}_{2} \mathrm{O}_{7}$, density $=2.56 \mathrm{~g} / \mathrm{cm}^{3}$ weighed versus brass in air, density $=1.16 \mathrm{mg} / \mathrm{cm}^{3}$.

$\mathrm{P}^{3+} / \mathrm{P}$ in table 2 is the mol ratio of trivalent phosphorus to total phosphorus in the products, equal to $0.00225 \nu / w)$.

The pressure of chlorine gas was about $980 \mathrm{mmHg}$; the average value of the temperature at the end of the reaction period was $24.87^{\circ} \mathrm{C}$.

The amount of $\mathrm{Mg}_{2} \mathrm{P}_{2} \mathrm{O}_{7}$ obtained from the $50-\mathrm{ml}$ aliquots (diluted to and treated as $200-\mathrm{ml}$ aliquots), was very close to exactly one fourth of that obtained from the $200-\mathrm{ml}$ aliquots. The average loss in the 50 - $\mathrm{ml}$ aliquots was only $0.001 \pm 0.051$ (std devn) $\mathrm{mg}$ $\mathrm{Mg}_{2} \mathrm{P}_{2} \mathrm{O}_{7}$, indicating that no correction is necessary

${ }^{5}$ The heat of chlorination of $\mathrm{PCl}_{3}$ to $\mathrm{PCl}_{5}$ is $29.6 \mathrm{kcal} / \mathrm{mol}$ [1].

TABLE 2. Results of the phosphorus chlorinations

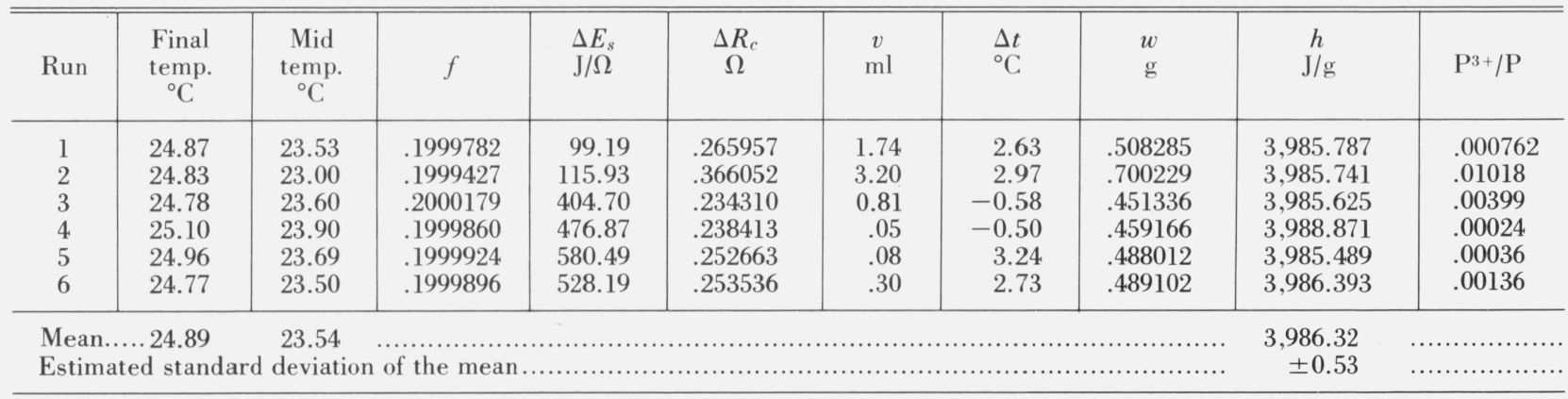


for loss of phosphorus during the double precipitation procedure.

Since there is no trend in the calculated value of $h$ with increasing mole fraction of trivalent phosphorus in the products (up to $1 \%$ ) we may conclude that the value taken for the molar heat correction for trivalent phosphorus contributes no appreciable systematic error. The heat calculated in this way is the enthalpy of reaction.

The estimated over-all standard deviation, taking into account other probable errors (see sec. 8), is $\pm 1.36 \mathrm{~J} / \mathrm{g} \mathrm{Mg} \mathrm{Mg}_{2} \mathrm{O}_{7}$. Therefore, using an uncertainty level which is twice the overall standard deviation [22], we obtain a value $-3,986.32 \pm 2.72 \mathrm{~J} / \mathrm{g} \mathrm{Mg}_{2} \mathrm{P}_{2} \mathrm{O}_{7}$ or $-443.585 \pm 0.303 \mathrm{~kJ} / \mathrm{mol} \mathrm{PCl} \mathrm{Pl}_{5} \quad(-106.019 \pm 0.072$ $\mathrm{kcal} / \mathrm{mol} \mathrm{PCl}_{5}$ ) for the enthalpy of reaction, at 24.89 ${ }^{\circ} \mathrm{C}$, of phosphorus with chlorine at $980 \mathrm{mmHg}$.

To adjust this value to the reaction taking place at $25^{\circ} \mathrm{C}$ with chlorine gas in the ideal state we must apply small corrections for the relative enthalpy of the chlorine (real gas) and the $\Delta C p^{\circ}$ of the reaction. From the work of Ross and Maass [23] we can derive a value of $-108 \mathrm{~J} / \mathrm{mol}$ for $\left(\mathrm{H}-\mathrm{H}^{\circ}\right)$ of chlorine gas at $298 \mathrm{~K}, 1.29 \mathrm{~atm}(980 \mathrm{mmHg})$. For $2 \mathrm{l} / 2 \mathrm{~mol}$ chlorine per g-atom phosphorus the enthalpy correction is $-270 \mathrm{~J} / \mathrm{g}$-atom $\mathrm{P}$.

The heat capacity at $25^{\circ} \mathrm{C}$ of $\mathrm{P}(c, \alpha)$ is $23.8 \mathrm{~J} /(\mathrm{g}$-atom $\mathrm{K})$ and of chlorine gas (ideal) is $33.9 \mathrm{~J} /(\mathrm{mol} \mathrm{K})$ [1]. There appears to be no value for the heat capacity of $\mathrm{PCl}_{5}(\mathrm{c})$ in the literature. However, the absolute entropy of $\mathrm{PCl}_{5}$ (c) at $298 \mathrm{~K}$ is estimated to be $39.8 \pm 2.0$ $\mathrm{cal} /(\mathrm{mol} \mathrm{K})[24]$. From this estimate, we may estimate that the specific heat is $120 \pm 50 \mathrm{~J} /(\mathrm{mol} \mathrm{K})$. Thus, the $\Delta C p^{\circ}$ of the reaction is $12 \pm 50 \mathrm{~J} /(\mathrm{mol} \mathrm{K})$ and, hence, the correction to $25^{\circ} \mathrm{C}$ is $1 \pm 2 \mathrm{~J} / \mathrm{mol}$.

The standard enthalpy of formation of $\mathrm{PCl}_{5}$ at $25^{\circ} \mathrm{C}$, therefore, is

$$
\begin{aligned}
\Delta H f_{298.15}^{\circ}\left[\mathrm{PCl}_{5}(c)\right] & =-443.854 \pm 0.303 \mathrm{~kJ} / \mathrm{mol} \\
& =-106.084 \pm 0.072 \mathrm{kcal} / \mathrm{mol} .
\end{aligned}
$$

This quantity corresponds to the reaction

$$
\mathrm{P}(c, \alpha)+\mathrm{Cl}_{2}(\mathrm{~g}) \rightarrow \mathrm{PCl}_{5}(c) .
$$

\section{Uncertainties}

The estimated maximum systematic error in the electrical calibration is $\pm 39 \mathrm{ppm}$. The uncertainties which contribute chiefly to this estimate are in the measurement of the voltage drop across the totalcurrent-measuring resistor $(12 \mathrm{mV} \pm 0.2 \mu \mathrm{V}$, i.e., 17 ppm) and the operation of the switching device $(750 \mathrm{~s}$ $\pm 0.02 \mathrm{~s}$, i.e., $27 \mathrm{ppm})$.

The estimated standard deviation of the mean of the calibration runs calculated by the method of Rossini $[22]$ is $0.44 \mathrm{~J} / \Omega$, which is $12 \mathrm{ppm}$.

The estimated maximum systematic error in the chemico-analytical determination of the amount of reaction is $312 \mathrm{ppm}$, obtained as the square root of the sum of the squares of the following probable errors: aliquot factor (for total phosphorus

determination):

phosphite determination

$200 \mathrm{ppm}$

$$
\begin{aligned}
& \frac{ \pm 0.1 \mathrm{ml} \times 0.040 \mathrm{~N}}{\text { aliquot }} \times \frac{1 \mathrm{mmol}}{2 \mathrm{mequiv}} \\
& \times \frac{1000 \mathrm{ml} / \mathrm{run}}{200 \mathrm{ml} / \text { aliquot }}= \pm 0.010 \mathrm{mmol} \mathrm{PCl}_{3} / \mathrm{run} \\
& \frac{ \pm 0.010 \mathrm{mmol} \mathrm{PCl} / \mathrm{run}}{22 \mathrm{mmol} \mathrm{total} \mathrm{P} / \mathrm{run}} \\
& \times \frac{29.7 \mathrm{cal} / \mathrm{mmol} \mathrm{PCl}_{3}}{106 \mathrm{cal} / \mathrm{mmol} \mathrm{PCl}_{5}}=
\end{aligned}
$$

weight corrections for weighing $\mathrm{Mg}_{2} \mathrm{P}_{2} \mathrm{O}_{7}$ :

$$
0.03 \mathrm{mg} / 0.5 \mathrm{~g}=
$$

$60 \mathrm{ppm}$

conversion of $\mathrm{H}_{3} \mathrm{PO}_{4}$ (aq) to $\mathrm{Mg}_{2} \mathrm{P}_{2} \mathrm{O}_{7}$ :

$$
0.1 \mathrm{mg} \mathrm{Mg}_{2} \mathrm{P}_{2} \mathrm{O}_{7} / 0.5 \mathrm{~g} \mathrm{Mg}_{2} \mathrm{P}_{2} \mathrm{O}_{7}
$$

$200 \mathrm{ppm}$

presence of phosphorus-chlorine compounds other than $\mathrm{PCl}_{3}$ and $\mathrm{PCl}_{5}$

(assumed)

0 ppm.

The estimated standard deviation of the mean of the chlorination runs is $0.53 \mathrm{~J} / \mathrm{g} \mathrm{Mg}_{2} \mathrm{P}_{2} \mathrm{O}_{7}$, i.e., $133 \mathrm{ppm}$.

The overall standard deviation assigned to the observed enthalpy of chlorination is taken as the square root of the sum of the squares of these four values according to the method of Rossini [22, p. 316]: $342 \mathrm{ppm} \times 3,986.32 \mathrm{~J} / \mathrm{g} \mathrm{Mg}_{2} \mathrm{P}_{2} \mathrm{O}_{7}= \pm 1.36 \mathrm{~J} / \mathrm{g} \mathrm{Mg}_{2} \mathrm{P}_{2} \mathrm{O}_{7}$.

\section{Discussion}

The references to papers we discuss in this section are summarized in table 3 . There are only two previous measurements of the enthalpy of chlorination of phosphorus; both measurements, carried out more than a hundred years ago, used white ${ }^{6}$ phosphorus. Abria [25] obtained $3199 \mathrm{cal} / \mathrm{g} \mathrm{P}$ (no details), i.e., $99.1 \mathrm{kcal} / \mathrm{mol}$. Andrews [26] reacted in a closed glass vessel at about atmospheric pressure a known volume of chlorine, measured dry at $11.4^{\circ} \mathrm{C}$ and $29.85 \mathrm{in} \mathrm{Hg}$, with an excess of phosphorus. In two runs he obtained 1924.6 and $1926.1 \mathrm{~g}$-cal/(1000 $\mathrm{cm}^{3} \mathrm{Cl}_{2}$ at $\left.0{ }^{\circ} \mathrm{C}, 1 \mathrm{~atm}\right)$. Average calorimeter temperature during the runs was $11.6^{\circ} \mathrm{C}$. The contribution of the reactants or products to the heat capacity of the system was about 0.1 percent of the total value and appears to have been neglected. Converting these values to conventional units we have:

\footnotetext{
${ }^{6}$ In the literature white phosphorus has consistently been regarded as the ordinary form; when the red form was used the investigator usually specified it as such. White phosphorus was also known as yellow phosphorus because of discoloration by an indeterminate though thermochemically negligible amount of the red variety.
} 
$\Delta U\left(11.6^{\circ} \mathrm{C}\right)=-1.9254 \times(22,413.6 / 1000)$

$\times 1.0135 \times 5 / 2 \times(4.1899 / 4.184)$

$=-109.499 \mathrm{kcal} / \mathrm{mol} \mathrm{P}$
If we assign an optimistic uncertainty of \pm 50 cal to Andrews' value for the reaction with $1000 \mathrm{~cm}^{3} \mathrm{Cl}_{2}$, we derive an uncertainty of $2.9 \mathrm{kcal} / \mathrm{mol} \mathrm{P}$ in the above molar enthalpy of reaction. It carries a negative bias, however, in that a considerable undetermined amount

TABLE 3. Important reactions in the thermochemistry of phosphorus

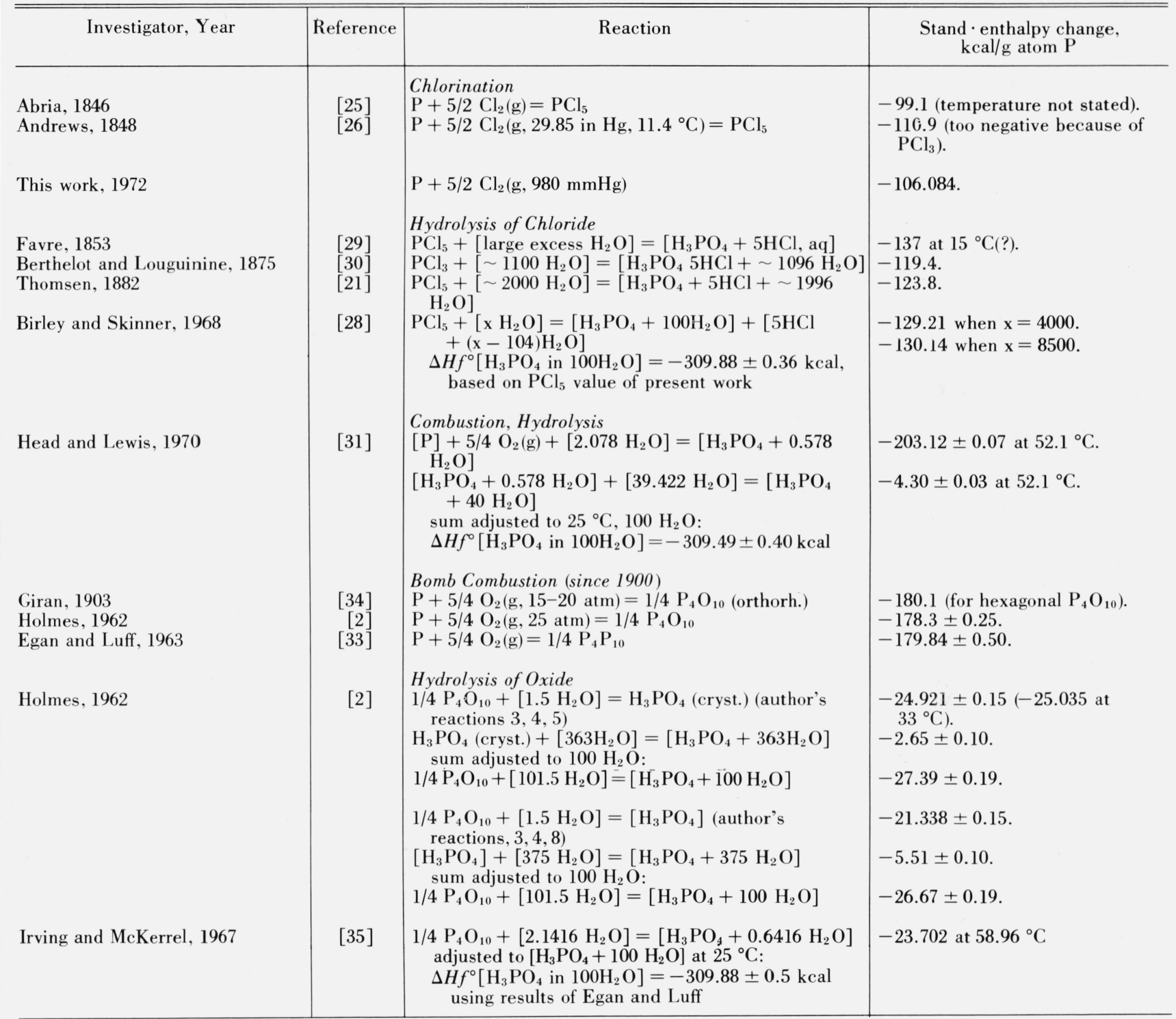

Unless otherwise specified, the states are crystalline (white $\mathrm{P}$; hexagonal $\mathrm{P}_{4} \mathrm{O}_{10}$ ), temperature is $25^{\circ} \mathrm{C}$; the term cryst. is used redundantly for emphasis.

$4.1899 \mathrm{~J} / \mathrm{g},{ }^{\circ} \mathrm{C}$ is the heat capacity of water at $11.6^{\circ} \mathrm{C}$ [27]. The value 1.0135 is the compressibility factor of chlorine at $11.4{ }^{\circ} \mathrm{C}$ and 29.85 in $\mathrm{Hg}$, evaluated from the third equation of p. 62 of reference [23]. Whence,

$\Delta H^{\circ}\left(25^{\circ} \mathrm{C}\right)=-109,499+(-(5 / 2) \mathrm{R}(284.55))$

$$
+(25-11.6)(3) \mathrm{cal}
$$

of $\mathrm{PCl}_{3}$, formed because of excess phosphorus, leads to a high value of liberated heat per mol $\mathrm{Cl}_{2}$.

The enthalpy of hydrolysis has been measured in four investigations, only one of which is recent. Birley and Skinner [28] measured the heat liberated at $25^{\circ} \mathrm{C}$ when crystalline vacuum-sublimed $\mathrm{PCl}_{5}$ was hydrolyzed to orthosphoric acid, $\mathrm{H}_{3} \mathrm{PO}_{4}$, in 4000 to $8500 \mathrm{~mol}$ of water, in an isoperibol ${ }^{7}$ solution calorimeter. Reac- 
tion times of up to 30 min were required for completion of the reaction. Separately measured values of the heat of mixing of $\mathrm{H}_{3} \mathrm{PO}_{4}(\mathrm{aq})$ with $\mathrm{HCl}(\mathrm{aq})$ in the same apparatus enabled them to calculate each run as a reaction whose products were $\mathrm{H}_{3} \mathrm{PO}_{4}$ in $100 \mathrm{~mol}$ of water, separate from the $\mathrm{HCl}(\mathrm{aq})$ produced. In calculating the $\Delta H f^{\circ}\left(\mathrm{H}_{3} \mathrm{PO}_{4}\right.$ in $\left.100 \mathrm{H}_{2} \mathrm{O}\right)$ from their calorimetric measurements they used our preliminary value [1], $\Delta H f^{\circ}\left(\mathrm{PCl}_{5}, c\right)=-106.0 \mathrm{kcal} / \mathrm{mol}$ based on the present work. Substituting our final value, we have, for the hydrolysis reaction of Birley and Skinner ${ }^{8}$

$$
\begin{aligned}
\Delta H f^{\circ}\left(\mathrm{H}_{3} \mathrm{PO}_{4} \text { in } 100 \mathrm{H}_{2} \mathrm{O}\right) & =-1296.6 \pm 1.5 \mathrm{~kJ} / \mathrm{mol} \\
& =-309.88 \pm 0.36 \mathrm{kcal} / \mathrm{mol} .
\end{aligned}
$$

Here, the uncertainty in $\mathrm{PCl}_{5}$ does not contribute appreciably to that assigned to $\mathrm{H}_{3} \mathrm{PO}_{4}$ (aq). The chief source of the uncertainty assigned by [28] is the slowness of the hydrolysis reaction. The hydrolysis of $\mathrm{PCl}_{5}$ in water takes place in two steps:

$$
\mathrm{PCl}_{5}(c)+\mathrm{H}_{2} \mathrm{O}(l) \rightarrow \mathrm{POCl}_{3}(l)+2 \mathrm{HCl}(\mathrm{aq})
$$

and

$$
\mathrm{POCl}_{3}(l)+3 \mathrm{H}_{2} \mathrm{O}(l) \rightarrow\left(\mathrm{H}_{3} \mathrm{PO}_{4}+3 \mathrm{HCl}\right)(\mathrm{aq}) .
$$

Although we performed no calorimetric hydrolyses, "bench-top" experiments in this laboratory indicated that if the $\mathrm{PCl}_{5}(c)$ is introduced into the water by breaking an evacuated ampoule, explosive evolution of $\mathrm{HCl}(\mathrm{g})$ occurs, according to the first reaction; if the ampoule contains air at about one atmosphere the initial step still is extremely rapid but not eruptive. The second step proceeds slowly at the interface between the two liquid phases with the moderate stirring which normally occurs in a calorimetric vessel, requiring up to 30 minutes as found by Birley and Skinner [28] and by Thomsen [21]. However, if the aqueous phase in the vicinity of the $\mathrm{POCl}_{3}(l)$ can be kept in an unstirred condition for a short time the heat of the second step warms the $\mathrm{POCl}_{3}(l)$ to its normal boiling point and the reaction is completed in about 5 min. We did not investigate the effect of using aqueous alkali or of increasing the stirring to break up the $\mathrm{POCl}_{3}$ into small drops.

The enthalpy of hydrolysis was measured also by Thomsen [21], giving $-123.2 \mathrm{kcal} / \mathrm{mol}$ at $22.6{ }^{\circ} \mathrm{C}$ in $2000 \mathrm{H}_{2} \mathrm{O}$, when adjusted to $25{ }^{\circ} \mathrm{C}:-123.8 \mathrm{kcal} / \mathrm{mol}$ ), and by Berthelot and Louguinine [30], giving -116.9 $\mathrm{kcal} / \mathrm{mol}$, in 1100 (?) $\mathrm{H}_{2} \mathrm{O}$ probably at $15^{\circ} \mathrm{C}$ (when adjusted to $25{ }^{\circ} \mathrm{C}$ : $\left.-119.4 \mathrm{kcal} / \mathrm{mol}\right)$. In citing these results we use an estimated $\Delta C p=-250 \mathrm{cal} /{ }^{\circ} \mathrm{C}$ for the reaction, correct the erroneous molecular weight used by Berthelot and Louguinine, and multiply their $0{ }^{\circ} \mathrm{C}$-calories by 1.0076 to convert to thermochemical calories. Favre $\lceil 29\rceil$ reported $\Delta H=-136.9 \mathrm{kcal} / \mathrm{mol}$ in a

\footnotetext{
${ }^{8}$ Here, and in instances to follow, we combine and compare our results, based on the 1969 Table of Atomic Weights, with other results, apparently based on the 1961 Table. How However, it does not seen necessary to make adjustments for this change because all recently published results reviewed in this paper seem to be calculated for a mole of reaction defined by the directly measured mass of $\mathrm{P}_{\text {or }} \mathrm{P}_{4} \mathrm{O}_{10}$ whose molecular weights were not changed. The decrease of $63 \mathrm{ppm}$ for $\mathrm{Mg}_{2} \mathrm{P}_{2} \mathrm{O}_{7}$, therefore, is not applicable here.
}

large excess of water, probably at $15^{\circ} \mathrm{C}$. A comparable result of Birley and Skinner at $25{ }^{\circ} \mathrm{C}$ in $4000 \mathrm{H}_{2} \mathrm{O}$ is $-129.2 \mathrm{kcal} / \mathrm{mol}$. Both Birley and Skinner [28] and Berthelot and Louguinine [30] found little dependence of the result on the $\mathrm{H}_{2} \mathrm{O} / \mathrm{PCl}_{5}$ ratio.

Another thermochemical route to aqueous orthophosphoric acid lies through the combustion of white phosphorus and hydrolysis of the resulting phosphorus pentoxide, ${ }^{9} \mathrm{P}_{4} \mathrm{O}_{10}$, by a strong aqueous acid at an elevated temperature. The phosphorus is usually protected by a combustible material, such as polyethylene, against premature reaction with oxygen. The use of glass ampoules has not been reported. There is a strong likelihood of reaction of the $\mathrm{P}_{4} \mathrm{O}_{10}$ with the glass; combustion reactions involving phosphorus are frequently accompanied by undesired interaction with other materials present [31, p. 702].

The most successful work along this line, and the most recent in the thermochemistry of aqueous orthophosphoric acid, seems to be that of Head and Lewis [31]. They measured the sum of the two steps as a single procedure burning polyethylene-encapsulated liquid phosphorus at $50{ }^{\circ} \mathrm{C}$ in oxygen, apparently at a pressure of $10 \mathrm{bar}$, in a platinum-lined rotating bomb containing 60 weight percent $\mathrm{HClO}_{4}$ as a hydrolytic medium. By a judicious choice of two other reactions at $50{ }^{\circ} \mathrm{C}$ in the same apparatus, errors in the estimated corrections to standard states (the "Washburn corrections") for the products of the reactions were made to cancel, although there were some side reactions for which corrections were required. As the sum of three separate reactions in the bomb they reported for

$$
\begin{aligned}
\mathrm{P}(l)+5 / 4 \mathrm{O}_{2}(\mathrm{~g})+2.078 & \stackrel{\mathrm{H}_{2} \mathrm{O}(l)}{\rightarrow}\left(\mathrm{H}_{3} \mathrm{PO}_{4}+0.578 \mathrm{H}_{2} \mathrm{O}\right) \\
\Delta U^{\circ}\left(52.1{ }^{\circ} \mathrm{C}\right)= & -846.51 \mathrm{~kJ} / \mathrm{mol}, \\
\Delta H^{\circ}\left(52.1{ }^{\circ} \mathrm{C}\right)= & -849.87 \mathrm{~kJ} / \mathrm{mol} .
\end{aligned}
$$

In the same apparatus they measured the enthalpy evolved upon further dilution of the $\mathrm{H}_{3} \mathrm{PO}_{4}$ to the concentration in $40 \mathrm{~mol}$ of water:

$$
\Delta H^{\circ}=\Delta U^{\circ}=-18.00 \pm 0.11 \mathrm{~kJ} / \mathrm{mol} \text { at } 50^{\circ} \mathrm{C} .
$$

Finally, adjusting to $25{ }^{\circ} \mathrm{C}$ by previously published values they derived:

$$
\Delta H f^{\circ}\left(\mathrm{H}_{3} \mathrm{PO}_{4} \text { in } 40 \mathrm{H}_{2} \mathrm{O}\right)=-1294.3 \pm 1.6 \mathrm{~kJ} / \mathrm{mol} \text {. }
$$

Diluting further [1], we can derive:

$\Delta H f^{\circ}\left(\mathrm{H}_{3} \mathrm{PO}_{4}\right.$ in $\left.100 \mathrm{H}_{2} \mathrm{O}\right)=-1294.9 \mathrm{~kJ} / \mathrm{mol}$

$$
=-309.49 \pm 0.40 \mathrm{kcal} / \mathrm{mol}
$$

in good agreement with the value based on the formation and hydrolysis of $\mathrm{PCl}_{5}$.

Attempts at a direct measure of the combustion step alone have not been entirely satisfactory. The difficulty

${ }_{9}^{9}$ Throughout this paper $\mathrm{P}_{4} \mathrm{O}_{10}$ signifies the hexagonal form of phosphorous pentoxide described by Hill, et al. [32]. 
seems to be in the uncertainty in the final products arising from the presence of water as a product of the combustion of the material used to enclose the phosphorus in order to prevent premature reaction.

The most reliable work on the combustion of phosphorus (white) appears to be that of Egan and Luff [33] who obtained widely scattered results in a steel bomb, most of them with coated phosphorus. One series of runs was performed in a double-compartment bomb in which uncoated phosphorus under helium was isolated from the pressurized-oxygen compartment until the beginning of the reaction period; although in this case the formation of water was avoided, the reaction was not complete. On the basis of selected runs in the various series (less than two thirds of those reported) they obtained $\Delta H f^{\circ}\left[\mathrm{P}_{4} \mathrm{O}_{10}(c\right.$, hex. $\left.)\right]=-719.4 \pm 2.0$ $\mathrm{kcal} / \mathrm{mol}$.

Holmes [2] carried out similar combustions of coated white phosphorus obtaining $-713.2 \pm 1.0 \mathrm{kcal} / \mathrm{mol}$.

Ignoring the work of the nineteenth century on the combustion of phosphorus [25], [26], which is of considerable historical interest (it is interesting to note here that Berthelot does not seem to have performed any phosphorus combustion), we might consider the work of Giran [34] who appears to have been the only one ever to carry out calorimetric combustion of phosphorus without interfering foreign substances. Working under carbon dioxide, he covered a solid fused mass of white phosphorus in a porcelain crucible with a light compact layer of red phosphorus which prevented oxidation until combustion was triggered in 15 to $20 \mathrm{~atm}$ pressure of oxygen in a porcelain-lined bomb. The adverse criticism by Holmes [2] with regard to Giran's handling of the phosphorus is not considered valid; it seems to have arisen from a misreading of Giran's text. Giran found the energy ( $-\Delta H$ ?) of combustion to be $184.7 \mathrm{kcal}$ per 31 grams of phosphorus. This value should be multiplied by 0.9937 to correct for air buoyancy during weighing of the phosphorus and for change in the accepted values of the enthalpies of combustion of the materials with which Giran calibrated his apparatus. Giran's product seems to have been the orthorhombic form of $\mathrm{P}_{4} \mathrm{O}_{10}$ (he called it amorphous) which is more stable than the common (hexagonal) form usually produced in bomb work and which has an enthalpy of formation which is 13.7 kcal more negative. The formation of orthorhombic $\mathrm{P}_{4} \mathrm{O}_{10}$ can be attributed to the slower cooling of the combustion product on the enamelled walls. With an additional adjustment (from 15 to $25{ }^{\circ} \mathrm{C}$ ) equal to $-0.073 \mathrm{kcal}$ we have

$$
\begin{aligned}
\Delta H f^{\circ}\left(\mathrm{P}_{4} \mathrm{O}_{10}, \text { hex. }\right)= & (-184.7) \times 0.9937 \times 4 \\
& +13.7-0.07=-720.5 \mathrm{kcal} / \mathrm{mol} .
\end{aligned}
$$

The enthalpy of hydrolysis of $\mathrm{P}_{4} \mathrm{O}_{10}$ has been measured at $58.96{ }^{\circ} \mathrm{C}$ by Irving and McKerrell [35] who used 62 percent $(9.6 \mathrm{~N})$ aq $\mathrm{HClO}_{4}$ for hydrolysis in an isoperibol solution calorimeter. By combining these results with those for two other dissolution reactions in the same apparatus they found the enthalpy of hydrolysis of $\mathrm{P}_{4} \mathrm{O}_{10}$ to form $4\left(\mathrm{H}_{3} \mathrm{PO}_{4}\right.$ in $0.6416 \mathrm{H}_{2} \mathrm{O}$ ) is $-94.807 \mathrm{kcal}$ : adjusted to $25{ }^{\circ} \mathrm{C}$ [36] and to $\mathrm{H}_{3} \mathrm{PO}_{4}$ in $100 \mathrm{H}_{2} \mathrm{O}\left(25^{\circ} \mathrm{C}\right)[1]:-110.260 \pm 0.035$ kcal. Holmes [2] measured the enthalpy of dissolution of $\mathrm{P}_{4} \mathrm{O}_{10}$ in $10.2 \mathrm{~N} \mathrm{HClO}_{4}$ at $33{ }^{\circ} \mathrm{C}$ in an adiabatic calorimeter; the results he obtained, using auxiliary reactions involving crystalline $\mathrm{H}_{3} \mathrm{PO}_{4}$, adjusted to $25{ }^{\circ} \mathrm{C}$ and $\mathrm{H}_{3} \mathrm{PO}_{4}$ in $100 \mathrm{H}_{2} \mathrm{O}$ are $-109.564 \mathrm{kcal}$; the use of auxiliary reactions involving liquid anhydrous $\mathrm{H}_{3} \mathrm{PO}_{4}$ led to values which were $0.7 \mathrm{kcal}$ more positive per mol $\mathrm{H}_{3} \mathrm{PO}_{4}$.

If the selected combustion results of Egan and Luff [33] are combined with the hydrolysis results of Irving and McKerrell [35] and the enthalpy of formation of liquid water [1], we have a third, closely agreeing, value by way of the two-step $\mathrm{P}_{4} \mathrm{O}_{10}$ route:

$$
\Delta H f^{\circ}\left(\mathrm{H}_{3} \mathrm{PO}_{4} \text { in } 100 \mathrm{H}_{2} \mathrm{O}\right)=-309.88 \pm 0.50 \mathrm{kcal} / \mathrm{mol} \text {. }
$$

On the basis of the present work and the other investigations cited above, we would recommend the following values, all at $298.15 \mathrm{~K}$ :

$$
\begin{gathered}
\Delta H f^{\circ}\left(\mathrm{PCl}_{5}, c\right)=-443.87 \pm 0.20 \mathrm{~kJ} / \mathrm{mol} \\
=-106.09 \pm 0.05 \mathrm{kcal} / \mathrm{mol}, \\
\begin{aligned}
& \Delta H f^{\circ}\left(\mathrm{P}_{4} \mathrm{O}_{10}, \text { hex }\right)=-3008.3 \pm 5.2 \mathrm{~kJ} / \mathrm{mol} \\
&=-719.0 \pm 1.3 \mathrm{kcal} / \mathrm{mol}, \\
& \Delta H f^{\circ}\left(\mathrm{H}_{3} \mathrm{PO}_{4} \text { in } 100 \mathrm{H}_{2} \mathrm{O}\right)=-1295.8 \pm 1.3 \mathrm{~kJ} / \mathrm{mol} \\
&=-309.7 \pm 0.3 \mathrm{kcal} / \mathrm{mol}
\end{aligned}
\end{gathered}
$$

This recommendation is in consonance with those of references [28] and [31].

\section{References}

[1] Wagman, D. D., Evans, W. H., Parker, V. B., Halow, I., Bailey, S. M., and Schumm, R. H., Nat. Bur. Stand. (U.S.) Tech. Note 270-3, (January 1968).

[2] Holmes, W. S., Trans. Faraday Soc. 58, 1916 (1962).

[3] MacRae, D., and Van Voorhis, C. C., J. Am. Chem. Soc. 43, 547 (1921).

[4] Prosen, E. J., and Rossini, F. D., J. Res. Nat. Bur. Stand. (U.S.) 33, 255 (1944).

[5] Prosen, E. J., Maron, F. W., and Rossini, F. D., J. Res. Nat. Bur. Stand. (U.S.) 46, 106 (1951).

[6] Rossini, F. D., Chapter 4 in Experimental Thermochemistry, F. D. Rossini, Editor, (Interscience Publishers, Inc., New York, New York, 1956).

[7] Greenfield, S., Chapter 5b in Comprehensive Analytical Chemistry, Vol. 1c C. L. Wilson and D. W. Wilson, Editors, (Elsevier Publ. Co., New York, 1962).

[8] Hoffman, J. I., and Lundell, G. E. F., J. Res. Nat. Bur. Stand. (U.S.) 5, 279 (1930).

[9] Hillebrand, W. F., Lundell, G. E. F., Bright, H. A., and Hoffman, J. I., Applied Inorganic Analysis, 2nd Edition, p. 638 (Wiley and Sons, New York, 1953).

[10] Duval, C., Inorganic Thermogravimetric Analysis, pp. 47, 99 (Elsevier Publ. Co., New York, 1953).

[11] Treadwell, F. P., and Hall, W. T., Analytical Chemistry, 9th English Edition, Vol. II, p. 258 (Wiley and Sons, New York, 1942).

[12] McNabb, W. C., J. Am. Chem. Soc. 49, 891 (1927).

[13] Penneman, R. A., and Audrieth, L. F., Anal. Chem. 20, 1058 (1948). 
[14] Wolf, L., and Jung, W., Z. anorg. u. allgem. Chem. 201, 337 (1931).

[15] Becker, W. E., and Johnson, R. E., J. Am. Chem. Soc. 79, 5157 (1957).

[16] Ebel, J. P., Mikrochim, Acta 1954, 679.

[17] Besson, A., and Fournier, Compt. rend. 150, 102 (1910).

[18] Sandoval, A. A., Moser, H. C., Inorg. Chem. 2, 27 (1963).

[19] Commission on Atomic Weights, IUPAC, Pure Appl. Chem. 21 , 91 (1970).

[20] Prosen, E. J., Chapter 6 in Experimental Thermochemistry, F. D. Rossini, Editor, (Interscience Publishers, Inc., New York, New York, 1956).

[21] Thomsen, J., Thermochemische Untersuchungen, Vol 2, pp. 322, 323 (Barth, Leipzig, 1882).

[22] Rossini, F. D., Chapter 14 in Experimental Thermochemistry, F. D. Rossini, Editor, (Interscience Publishers, Inc., New York, 1956).

[23] Ross, A. S., and Maass, O., Can. J. Research 18B. 55 (1940).

[24] Kelley, K. K., and King, E. G., U.S. Bur. Mines Bull. No. 592, p. 75, (U.S. Government Printing Office, Washington, D.C. 20402, 1961)

[25] Abria, Compt. rend. 22, 372 (1846); his paper in Annali di Fisica, Chimica e Matematiche 24, 269 (1846) is an Italian translation of this.

[26] Andrews, T., Phil. Mag. [3], 32, 321-339, 426-434 (1848). This is considered to be the first bomb calorimeter, though compressed gas was not used-see Partington, J. R., The History of Chemistry, Vol. 4, p. 609 (MacMillan and Co., London, 1964); Ostwald, W., Outlines of Gen. Chem., transl. by J. Walker, p. 215 (MacMillan and Co., London, 1890).

[27] Osborne, N. S., Stimson, H. F., and Ginnings, D.C., Nat. Bur. Stand. (U.S.) Handb. 77, Vol. II, p. 318.

[28] Birley, G. I., and Skinner, H. A., Trans. Faraday Soc. 64, 3232 (1968).

[29] Favre, P.-A., J. pharm. chim. [3] 24, 328 (1853).

[30] Berthelot and Louguinine, Ann. chim. et phys. [5] 6, 305 (1875). (1875).

[31] Head, A. J., and Lewis, G. B., J. Chem. Thermodynamics 2, 701 (1970).

[32] Hill, W. L., Faust, G. T., and Hendricks, S. B., J. Am. Chem. Soc. 65, 794 (1943).

[33] Egan, E. P., Jr., and Luff, B. B., Progress Report, June 1Nov. 30, 1963, Tennessee Valley Authority, AD 429008. (Natl. Tech. Info. Service, 5285 Port Royal Road, Springfield, VA 22151).

[34] Giran, H., Ann. chim. et phys. [7] 30, 203 (1903).

[35] Irving, R. J., and McKerrell, H., Trans. Faraday Soc. 63, 2582 (1967).

[36] Egan, E. P., Jr., Luff, B. B., and Wakefield, Z. T., J. Phys. Chem. 62, 1091 (1958); the revisions published in J. Chem. Eng. Data 7, 385 (1962) do not apply here.

(Paper 78A3-818) 